Article

\title{
The Effect of Salt on the Complex Coacervation of Vinyl Polyelectrolytes
}

\section{Sarah L. Perry ${ }^{1, *}$, Yue Li ${ }^{1}$, Dimitrios Priftis ${ }^{1}$, Lorraine Leon ${ }^{1,2}$ and Matthew Tirrell ${ }^{1,2}$}

1 Institute for Molecular Engineering, University of Chicago, 5747 South Ellis Avenue, Jones 222, Chicago, IL 60637, USA; E-Mails: liyue19916@gmail.com (Y.L.); dpriftis@uchicago.edu (D.P.); lorraineleon@uchicago.edu (L.L.); mtirrell@uchicago.edu (M.T.)

2 Argonne National Laboratory, 9700 South Cass Avenue, Argonne, IL 60439, USA

* Author to whom correspondence should be addressed; E-Mail: perrys@uchicago.edu; Tel.: +1-773-834-2001; Fax: +1-773-834-7756.

Received: 5 May 2014; in revised form: 3 June 2014 / Accepted: 4 June 2014 /

Published: 16 June 2014

\begin{abstract}
Complex coacervation is an electrostatically-driven phase separation phenomenon that is utilized in a wide range of everyday applications and is of great interest for the creation of self-assembled materials. Here, we utilized turbidity to characterize the effect of salt type on coacervate formation using two vinyl polyelectrolytes, poly(acrylic acid sodium salt) (pAA) and poly(allylamine hydrochloride) (pAH), as simple models for industrial and biological coacervates. We confirmed the dominant role of salt valence on the extent of coacervate formation, while demonstrating the presence of significant secondary effects, which can be described by Hofmeister-like behavior. These results revealed the importance of ion-specific interactions, which are crucial for the informed design of coacervate-based materials for use in complex ionic environments, and can enable more detailed theoretical investigations on the role of subtle electrostatic and thermodynamic effects in complex coacervation.
\end{abstract}

Keywords: complex coacervation; polyelectrolyte complex; ionic strength; multivalent; charge density; poly(acrylic acid); poly(allylamine) 


\section{Introduction}

Electrostatically-driven self assembly can be tuned through a variety of parameters, including the chemical nature of the charged species, the size or length of the charged particle or molecule, particle shape, polydispersity, charge density, $\mathrm{pH}$, and ionic strength [1-14]. Consideration of these variables is critical in the design of self-assembled materials. For instance, electrostatic complexation between oppositely-charged polyelectrolytes has been used in drug and gene delivery [7,14-18], thin film coatings [19-21], processed food [22], and underwater adhesives [23-26]. Clearly, the functionality of the material must be considered in the context of the operational environment. As an example, the stability requirements for a material to be used in seawater (i.e., $\sim 700 \mathrm{mM} \mathrm{NaCl}$ and $\mathrm{pH} \sim 7.4-8.4$ ) are significantly different from the requirements for stability under physiological conditions (i.e., $\sim 150 \mathrm{mM} \mathrm{KCl}$, $\sim 20 \%-40 \%$ proteins by mass, and $\mathrm{pH} \sim 7.4$ in the cytosol) [25,27-31]. In order to achieve efficient materials design, it is necessary to develop a broader understanding of the role of individual parameters on materials self-assembly, rather than relying on application-specific investigations.

Complex coacervation is a specific type of polyelectrolyte complexation, defined by a liquid-liquid phase separation [32]. When aqueous solutions of oppositely-charged polyelectrolytes are mixed, the resultant liquid complexes cause the solution to appear cloudy, due to the formation of a dispersion of dense, polymer rich droplets (Figure 1a). These droplets can then coalesce into a polymer rich coacervate phase in equilibrium with a polymer poor solution phase (Figure 1b) [1-9,33-35].

Figure 1. (a) Optical micrograph of the dispersion of liquid coacervate droplets formed in the presence of $700 \mathrm{mM} \mathrm{NaCl}$. Imaging was performed using an ultra-low attachment 96-well plate (Costar, Corning Inc., Corning, NY, USA). (b) Photograph of the coalesced coacervate phase from (a) after centrifugation. All samples were prepared at $1 \mathrm{mM}$ total monomer concentration using a 50/50 mol\% poly(acrylic acid sodium salt) (pAA)/poly(allylamine hydrochloride) $(\mathrm{pAH})$ ratio at $\mathrm{pH}$ 6.5. Complexes were prepared by adding pAA to a solution containing a mixture of $\mathrm{pAH}$ and the desired quantity of salt.
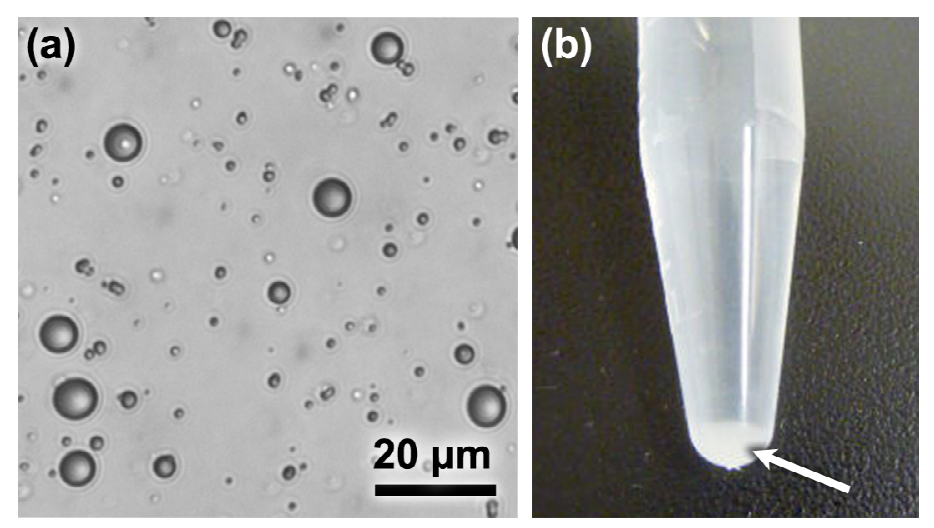

The overall formation of complex coacervates is strongly dependent upon solution conditions (i.e., $\mathrm{pH}$ and ionic strength), and is driven through a combination of attractive electrostatic forces and entropically-favorable molecular rearrangements, where the loss of configurational entropy caused by the electrostatic interaction of oppositely-charged polyelectrolytes is counterbalanced by the release of small, bound, counter-ions from the polyelectrolyte salts into solution [2,6,14,36-41]. This critical 
entropic dependence on the release of counter-ions is considered to be the main reason why complex coacervation is sensitive to the overall concentration of salt ions present. High salt concentrations decrease the entropic driving force for complex formation and ultimately destabilize the liquid-liquid phase separation [1-3,11,12,36,42-44]. In contrast to this inhibitory effect on complex formation under conditions of high salt, the presence of small amounts of salt may, in fact, enhance complex formation by softening electrostatic interactions, favoring more accessible polymer conformations, and enabling chain rearrangement $[4,36,45]$.

While the effects of salt on complex coacervation have been well studied in model systems, the majority of these studies have focused only on the impact of $\mathrm{NaCl}$ as a simple monovalent salt $[1,2,4-6,8-10,33,34,36,46-51]$. Those studies which have examined the impact of multivalent salts on polyelectrolyte complexation have either investigated systems which form solid complexes rather than liquid coacervates [39], or have utilized biologically-derived polymers and/or proteins [22,52,53]. For instance, a wide range of polysaccharides have been utilized in coacervation, particularly for applications related to the food industry [22]. However, these biologically-derived polysaccharides tend to be poorly defined chemically, as well as polydisperse. The use of proteins can also be challenging because of the difficulty in defining a charge density for the system and the potential for specific protein-salt interactions $[14,45]$. Thus, while the field has developed a primary quantitative understanding of the role of monovalent ions in coacervation processes, the effects of ionic species and higher valences remain unstudied. Although we can reasonably anticipate that the valence of the salt ions should dominate the electrostatics of the system, it is not known whether these type of effects do, in fact, scale directly with ionic strength. Additionally, more subtle effects (e.g., ion size, ion hydration, dispersion effects, and polarizability), which are inseparable and have been correlated to Hofmeister series effects) are even more challenging to predict $[54,55]$.

In this report, we systematically examine the effects of various salts on the complex coacervation of two vinyl polyelectrolytes, poly(acrylic acid sodium salt) (pAA) and poly(allylamine hydrochloride) (pAH). By using this type of well-controlled model system, we eliminate effects that could be attributable to differences in the interaction of the polymer backbone with the environment, or differences in polymer hydrophobicity resulting from different side-chain lengths. The molecular weight of the polymers used in this study was also chosen to minimize potential variation associated with differences in polymer chain length. Turbidity was used to measure the extent of complex formation and investigate variations in the stability of coacervates with respect to the addition of salts of different ion type and valence, as well as polymer-based charge effects. In addition to examining the general effects of monovalent and divalent salts, we compare various sodium salts to test for subtle anionic effects, and a series of chloride salts to test for analogous cationic effects. Specific attention is given to sodium and potassium salts because of the relevance of these ions in biological systems. Finally, we also discuss the relationship between salt effects and polyelectrolyte charge density by examining the consequences of varying $\mathrm{pH}$. 


\section{Experimental Section}

\subsection{Materials}

Poly(acrylic acid sodium salt) (pAA) was purchased as a $35 \mathrm{wt} \%$ solution in water (Sigma-Aldrich, St. Louis, MO, USA) while poly(allylamine hydrochloride) (pAH) was purchased as a dry powder (Sigma-Aldrich). Both polymers have an average $M_{\mathrm{w}} \sim 15,000$, as reported by the manufacturer, corresponding to a degree of polymerization $N \sim 160$. Polymers were used without further processing. pAA is a weak acid with a pKa around $\mathrm{pH} 4.5$, while $\mathrm{pAH}$ is a weak base with a pKa around $\mathrm{pH} 8.5$ [9]. Stock solutions were prepared gravimetrically using Milli-Q water (resistivity of $18.2 \mathrm{M} \Omega \mathrm{cm}$, Millipore, Billerica, MA, USA) at a concentration of $10 \mathrm{mM}$ with respect to the number of monomers (i.e., the number of acid or base groups) present in solution and then adjusted to their final $\mathrm{pH}$ ( 6.5 or 8.5) using concentrated solutions of $\mathrm{HCl}$ and $\mathrm{NaOH}$, as needed. Monomer concentration was chosen as the experimental basis in order to easily enable direct stoichiometric comparison of the number of positively and negatively charged units present in solution, regardless of $\mathrm{pH}$.

Stock solutions of various salts were prepared gravimetrically and adjusted to their final $\mathrm{pH}$ (6.5 or 8.5), as above. At pH 6.5 the following solutions were prepared: $2 \mathrm{M}$ and $5 \mathrm{M}$ sodium chloride $(\mathrm{NaCl}$, ACS reagent, $\geq 99 \%$, Acros Organics, Geel, Belgium), $2 \mathrm{M}$ and $5 \mathrm{M}$ sodium bromide ( $\mathrm{NaBr}$, certified ACS, $\geq 99 \%$, Fisher Scientific, Waltham, MA, USA), $2 \mathrm{M}$ and $5 \mathrm{M}$ sodium iodide (NaI, molecular biology grade, $\geq 99 \%$, Fisher Scientific), $2 \mathrm{M}$ and $5 \mathrm{M}$ sodium nitrate $\left(\mathrm{NaNO}_{3}\right.$, biochemistry grade, $\geq 99 \%$, Acros Organics), $2 \mathrm{M}$ and $5 \mathrm{M}$ sodium acetate trihydrate $\left(\mathrm{NaCOOCH}_{3} \cdot 3 \mathrm{H}_{2} \mathrm{O}\right.$, Fisher Scientific), $1 \mathrm{M}$ sodium phosphate dibasic heptahydrate $\left(\mathrm{Na}_{2} \mathrm{HPO}_{4} \cdot 7 \mathrm{H}_{2} \mathrm{O}\right.$, certified ACS, Fisher Scientific), $2 \mathrm{M}$ sodium sulfate decahydrate $\left(\mathrm{Na}_{2} \mathrm{SO}_{4} \cdot 10 \mathrm{H}_{2} \mathrm{O}\right.$, Acros Chemical), $2 \mathrm{M}$ magnesium chloride hexahydrate $\left(\mathrm{MgCl}_{2} \cdot 6 \mathrm{H}_{2} \mathrm{O}\right.$, BioXtra, $\geq 99 \%$, Sigma-Aldrich), $2 \mathrm{M}$ calcium chloride dehydrate $\left(\mathrm{CaCl}_{2} \cdot 2 \mathrm{H}_{2} \mathrm{O}\right.$, ACS reagent, $\geq 99 \%$, Acros Organics), $1 \mathrm{M}$ trisodium citrate dehydrate $\left(\mathrm{Na}_{3} \mathrm{C}_{6} \mathrm{H}_{5} \mathrm{O}_{7} \cdot 2 \mathrm{H}_{2} \mathrm{O}\right.$, certified, Fisher Scientific), 4.5 M potassium chloride (KCl, BioXtra, $\geq 99 \%$, Sigma-Aldrich, St. Louis, MO), $3.5 \mathrm{M}$ potassium nitrate $\left(\mathrm{KNO}_{3}\right.$, ReagentPlus, $\geq 99 \%$, Sigma-Aldrich), and $0.63 \mathrm{M}$ potassium sulfate $\left(\mathrm{K}_{2} \mathrm{SO}_{4}\right.$, $\geq 99 \%$, Sigma-Aldrich). At $\mathrm{pH} 8.5$, the following solutions were prepared: $2 \mathrm{M}$ and $5 \mathrm{M} \mathrm{NaCl}, 1 \mathrm{M}$ $\mathrm{Na}_{2} \mathrm{HPO}_{4} \cdot 7 \mathrm{H}_{2} \mathrm{O}, 2 \mathrm{M} \mathrm{Na}_{2} \mathrm{SO}_{4} \cdot 10 \mathrm{H}_{2} \mathrm{O}, 2 \mathrm{M} \mathrm{CaCl}_{2} \cdot 2 \mathrm{H}_{2} \mathrm{O}$, and $1 \mathrm{M} \mathrm{Na}_{3} \mathrm{C}_{6} \mathrm{H}_{5} \mathrm{O}_{7} \cdot 2 \mathrm{H}_{2} \mathrm{O}$.

\subsection{Preparation of Polyelectrolyte Complexes}

Complexation is achieved by mixing aqueous solutions of pAA and pAH, typically in the presence of salt. Samples were prepared by first mixing a concentrated salt solution with MilliQ water in a microcentrifuge tube (1.5 mL, Eppendorf, Hamburg, Germany), followed by sequential addition of the polycation $(\mathrm{pAH})$ and then the polyanion (pAA) to a final volume of $500 \mu \mathrm{L}$. The mixture was vortexed for $5 \mathrm{~s}$ immediately after the addition of each solution. For all experiments, samples were prepared to a final concentration of $1 \mathrm{mM}$ monomers (total cation and anion). An analysis of the effect of polyelectrolyte stoichiometry was performed at $\mathrm{pH} 6.5$ and $\mathrm{pH} 8.5$ in the presence of no salt and $100 \mathrm{mM} \mathrm{NaCl}$ over compositions ranging from 10/90 mol\% to 90/10 mol\% pAA/pAH. Taking into account the effects of $\mathrm{pH}$, charge-neutral or isoelectric conditions correspond to a $50 / 50 \mathrm{~mol} \%$ pAA/pAH mixture at pH 6.5 and a 33/67 mol\% pAA/pAH composition at $\mathrm{pH} 8.5$. The effect of salt 
was examined at these charge-neutral conditions at $\mathrm{pH} 6.5$ and $\mathrm{pH} 8.5$ over the range of 0 to $4.5 \mathrm{M}$ salt. All samples were prepared immediately before analysis and studied at room temperature $\left(25^{\circ} \mathrm{C}\right)$.

\subsection{Turbidity Measurements}

Turbidity was used to qualitatively measure of the extent of coacervation as a function of charge stoichiometry and salt concentration. Turbidity measurements were made using a plate reader equipped with a UV spectrophotometer (Tecan, Infinite M200 P80, Männedorf, Switzerland). Turbidity was measured at a wavelength of $550 \mathrm{~nm}$ and a temperature of $25^{\circ} \mathrm{C}$. None of the polymers absorb light at this wavelength. Turbidity is defined as $-\ln \left(I / I_{0}\right)$, with $I_{0}=$ incident light intensity and $I=$ intensity of light passed through the sample volume, and is measured in absorption units (a.u.).

After preparation, $100 \mu \mathrm{L}$ of sample was pipetted in triplicate into a 96-well plate (black/clear with lid, BD Falcon, San Jose, CA, USA) for analysis. Triplicate measurements were made for each well, and all experiments were repeated three times. Error bars on turbidity plots represent the calculated standard deviation of the data. All samples were referenced to an empty well plate.

\subsection{Visual Characterization of Complexes}

Visual inspection and optical microscopy were used to confirm the presence of liquid coacervates and identify the critical salt transition where only no phase separation occurs. Optical phase contrast microscopy (Leica DMI 6000B using Leica Application Suite (LAS) image acquisition software, Wetzlar, Germany) enabled direct visualization of spherical coacervate droplets (Figure 1a). For the salt studies, samples with a final salt concentration of $50 \mathrm{mM}, 300 \mathrm{mM}$, and $700 \mathrm{mM}$ were pipetted onto a glass slide for imaging.

For visual inspection, samples were centrifuged (accuSpin Micro 17, Fisher Scientific) for 15 min at $10,000 \mathrm{rpm}$ to coalesce the dispersed complexes to a single phase at the bottom of the microcentrifuge tube (Figure 1b).

\section{Results and Discussion}

Here, we begin with a brief characterization of complex coacervation in our model system as a function of charge stoichiometry (Section 3.1). Utilizing the optimal conditions for coacervate formation identified in Section 3.1, we then explore the effects of various salts on complex formation (Section 3.2). Finally, we examine the interplay between coacervate stability as a function of salt concentration and polymer charge density by examining the effects of varying $\mathrm{pH}$ (Section 3.3). In these studies, turbidimetry, coupled with optical microscopy, was used to provide a qualitative measure of the extent of complex formation.

\subsection{The Effect of pH on Coacervate Stoichiometry}

The most direct variable for controlling coacervate formation is the charge stoichiometry, or the molar ratio of polycation (pAH) to polyanion (pAA), in the system. Both of the polymers used in this study are weak polyelectrolytes; the $\mathrm{pKa}$ for $\mathrm{pAA}$ is around $\mathrm{pH} 4.5$, while the $\mathrm{pKa}$ for $\mathrm{pAH}$ is around $\mathrm{pH} 8.5$ [9]. Consequently, we made the assumption that at $\mathrm{pH} 6.5$, which is two $\mathrm{pH}$ units away from 
the $\mathrm{pKa}$ of each polymer, both polyelectrolytes should be both fully and equally charged. Additionally, the data reported here were obtained by adding pAA to a solution containing a mixture of pAH and the desired quantity of salt. However, we did not observe significant variation in our data as a result of reversing the order of polyelectrolyte addition.

For the symmetric case at $\mathrm{pH} 6.5$ where both polymers are of equal length and equal charge, we observe a maximum in coacervate formation close to $50 / 50 \mathrm{~mol} \% \mathrm{pAA} / \mathrm{pAH}$ (Figure 2, black circles). This composition corresponds to the condition of charge neutrality in the system, where the number of charges from the polycation $(\mathrm{pAH})$ equals the number of charges from the polyanion (pAA). Furthermore, the turbidity signal is sharply peaked around this charge-neutral condition, in agreement with previous reports $[4,5,9,10]$, indicating the critical role of electrostatic effects in facilitating complex formation. However, it should be noted that under conditions of no salt, the maximum turbidity appears to be slightly lower than the ideal $50 / 50 \mathrm{~mol} \% \mathrm{pAA} / \mathrm{pAH}$ composition. This slight shift could be the result of local $\mathrm{pH}$ effects associated with the interaction of the two polymers with each other. The addition of $100 \mathrm{mM} \mathrm{NaCl}$ appears to mitigate this effect, suggesting the ability of salt to moderate local $\mathrm{pH}$ effects [56]. However, further investigation of this phenomenon is beyond the scope of this work.

We further investigated the effects of charge stoichiometry by examining coacervate formation at $\mathrm{pH} 8.5$, corresponding to the $\mathrm{pKa}$ value of $\mathrm{pAH}$. By definition, at the $\mathrm{pKa}$ a polyelectrolyte is only half-charged. As shown in Figure 2, changing the $\mathrm{pH}$ from 6.5 to 8.5 caused the location of maximum coacervate formation to shift from approximately 50/50 mol\% pAA/pAH to $33 / 67 \mathrm{~mol} \% \mathrm{pAA} / \mathrm{pAH}$ (Figure 2, blue squares). The location of this peak again corresponds to the charge-neutral condition for optimal complexation. Due to the fact that $\mathrm{pAH}$ is only half-charged at $\mathrm{pH} 8.5$, twice as much $\mathrm{pAH}$ is required to create a charge-neutral complex (i.e., two pAH chains for every one pAA, or a ratio of 33/67 mol\% pAA/pAH).

Figure 2. Plot of turbidity as a function of the mole fraction of the polycation $(\mathrm{pAH})$ at pH 6.5 where both polymers are fully charged (black circles) and pH 8.5 where pAH is only half-charged (blue squares). Data are shown for conditions of no salt (open symbols) and $100 \mathrm{mM} \mathrm{NaCl}$ (closed symbols). All samples were prepared at $1 \mathrm{mM}$ total monomer concentration. Complexes were prepared by adding pAA to a solution containing a mixture of pAH and the desired quantity of salt.




We also examined the effect of salt on the extent of coacervate formation with respect to charge stoichiometry. Whereas the stoichiometry curves were very sharply peaked in the absence of salt, the addition of $100 \mathrm{mM} \mathrm{NaCl}$ resulted in an increase in both the overall turbidity signal and the range of compositions over which coacervation was observed. This broadening of the compositional range for coacervation is thought to be a result of charge screening effects, where salt is able to interact with the polyelectrolyte and provide local compensation for the charge imbalance [56,57]. Similarly, the increase in overall signal could be the result of enhanced complexation (i.e., more droplets in solution), or swelling due to increased water content (i.e., larger droplets) [4,47].

\subsection{The Effect of Salt on Coacervate Formation}

Building on the results obtained in Section 3.1, we examined the effects of increasing concentrations of various monovalent and divalent salts on complex coacervates formed at an optimal polymer stoichiometry (50/50 mol\% $\mathrm{pAA} / \mathrm{pAH}$ at $\mathrm{pH} 6.5$ or $33 / 67 \mathrm{~mol} \% \mathrm{pAA} / \mathrm{pAH}$ at $\mathrm{pH} 8.5)$.

Figure $3 \mathrm{a}$ shows a plot of turbidity as a function of salt concentration for monovalent $\mathrm{NaCl}$, as well as for $\mathrm{Na}_{2} \mathrm{SO}_{4}$ and $\mathrm{CaCl}_{2}$, which possess divalent anions and cations, respectively. In agreement with the enhancement of coacervation observed in Section 3.1, and with previous literature reports $[4,5,9,10]$, the addition of small amounts of salt $(<75 \mathrm{mM})$ increases the amount of complex formed (i.e., the size and number of droplets observed). However, further addition of salt causes a decrease in the turbidity signal until the point where phase separation is no longer observed. This concentration is referred to as the critical salt concentration $[1-3,9,10,33,44]$.

Figure 3. Plots of turbidity as a function of (a) salt concentration and (b) ionic strength for a selection of monovalent and divalent salts. All samples were prepared at $1 \mathrm{mM}$ total monomer concentration, $50 / 50 \mathrm{~mol} \% \mathrm{pAA} / \mathrm{pAH}$ ratio at $\mathrm{pH}$ 6.5. Complexes were prepared by adding pAA to a solution containing a mixture of $\mathrm{pAH}$ and the desired quantity of salt.
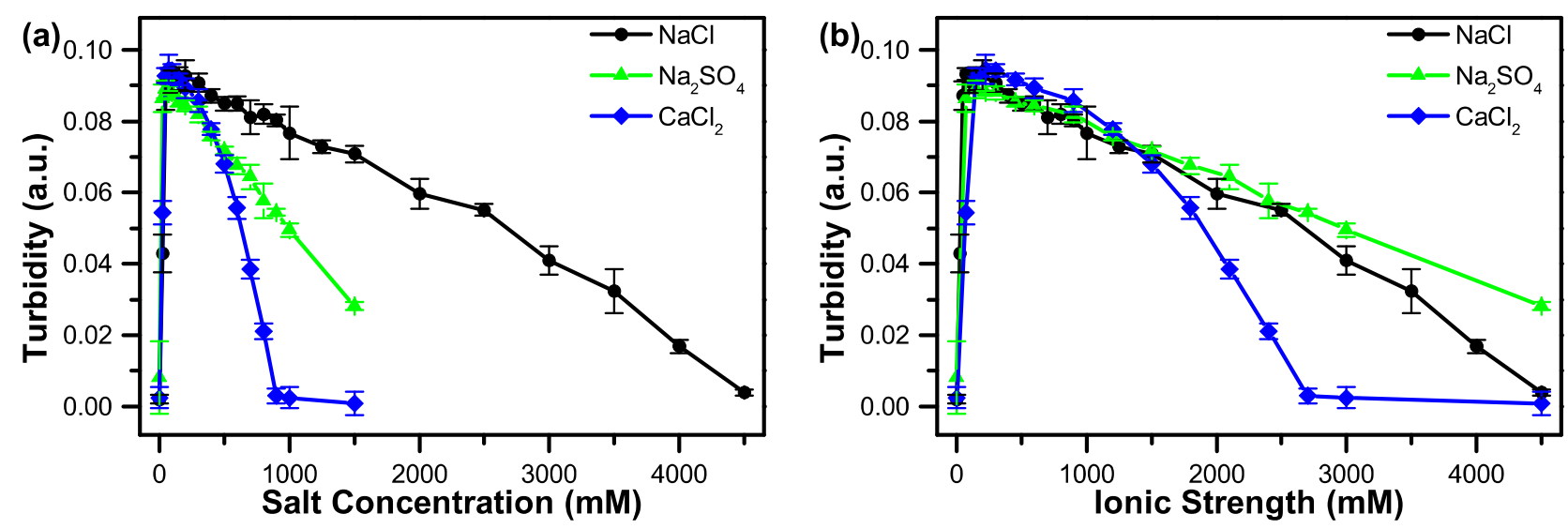

Compared with previous reports, the $\mathrm{pAA} / \mathrm{pAH}$ system examined here at $\mathrm{pH} 6.5$ shows extremely high stability in $\mathrm{NaCl}$. Examination of Figure 3 suggests that the critical $\mathrm{NaCl}$ concentration for this system is above $4.5 \mathrm{M} \mathrm{NaCl}$. This is a significantly higher critical salt concentration than has been suggested previously $[9,10]$. This dramatic difference in critical salt concentration appears to be the result of subtle differences in the electrostatics of the system during mixing. In the experiments we report here, all solutions were adjusted to a $\mathrm{pH}$ of 6.5 prior to complexation, whereas in the previous 
work by Chollakup et al., the $\mathrm{pH}$ of the pAA and $\mathrm{pAH}$ were significantly different (i.e., $\mathrm{pH} 8.5$ for pAA and $\mathrm{pH} 3.0$ for $\mathrm{pAH}$ ), but stabilized at a value near 6.5 after complexation $[9,10]$. Further investigations are needed to identify the mechanism responsible for this difference.

While the turbidity data suggests a critical salt concentration above $4.5 \mathrm{M}$ for $\mathrm{NaCl}$, divalent salts such as $\mathrm{Na}_{2} \mathrm{SO}_{4}$ and $\mathrm{CaCl}_{2}$ are much more efficient at preventing coacervate formation (Figure 3a). Despite the divalent nature of both salts, $\mathrm{CaCl}_{2}$ has a more inhibitory effect on coacervation per unit concentration than $\mathrm{Na}_{2} \mathrm{SO}_{4}$. Furthermore, Figure $3 \mathrm{~b}$ reveals that, per unit of ionic strength, $\mathrm{Na}_{2} \mathrm{SO}_{4}$ has the smallest impact on coacervation, less than even $\mathrm{NaCl}$. The difference in the impact of $\mathrm{CaCl}_{2}$ and $\mathrm{Na}_{2} \mathrm{SO}_{4}$ can be explained in terms of the "hardness" of the $\mathrm{Ca}^{2+}$ ion compared to $\mathrm{SO}_{4}{ }^{2-}[58,59] . \mathrm{Ca}^{2+}$ is a very compact, "hard" ion, where the charge is localized around a single atomic point, creating an area of high charge density. This is in contrast to $\mathrm{SO}_{4}{ }^{2-}$, which is a more diffuse molecular ion where the charge is spread out over multiple atoms.

The differences between the various ions at equivalent ionic strength can be further explained in terms of the Hofmeister series [55], or the strength of their interaction with the polymer. The Hofmeister series was originally formulated based on the tendency for various salts to aggregate or solubilize proteins [60]. $\mathrm{SO}_{4}{ }^{2-}$ is considered to be a kosmotrope, which tends to "salt out," or decrease the solubility of a polymer with increasing salt concentration. $\mathrm{Cl}^{-}$, on the other hand, is considered to be a relatively inert anion that has little effect on polymer solubility [55]. In terms of coacervation, the kosmotropic tendency of $\mathrm{SO}_{4}{ }^{2-}$ to decrease polymer solubility would actually enhance phase separation, thus increasing the critical salt concentration compared to $\mathrm{Cl}^{-}$, as suggested in Figure $3 \mathrm{~b}$.

The opposite behavior is observed for $\mathrm{Ca}^{2+}$, which is considered to be more chaotropic than $\mathrm{Na}^{+}$. Chaotropic ions tend to "salt in," or increase the solubility of polymers, thus disfavoring phase separation, and accounting for the lower critical salt ionic strength observed for $\mathrm{Ca}^{2+}$ as compared to $\mathrm{Na}^{+}$. Additionally, chaotropes tend to favor aqueous interfaces [55], which would result in an increased tendency to interact with the water-polyelectrolyte boundary, negating the entropic benefits associated with counter-ion release and further disfavoring coacervation.

The trends observed in the Hofmeister series correlate with the "hardness," or the free energies of hydration of the various ions [58,59,61-63]. The Principle of Hard and Soft Acids and Bases (HSAB) states that "hard" acids prefer to interact with "hard" bases. Similarly, stronger electrostatic interactions are observed between ions with matching hydration energies [61-63]. Comparing the interactions between the cationic polymer side-chains and the anionic salts, the apparent dynamic hydration number $(\mathrm{ADHN})$, or the number of tightly bound water molecules, is approximately zero for both amine groups $\left(\mathrm{NH}_{4}^{+}\right)$, as in $\mathrm{pAH}$, and $\mathrm{Cl}^{-}$[61,64], suggesting the potential for a strong electrostatic interaction. However, the $\mathrm{ADHN}$ for $\mathrm{SO}_{4}{ }^{2-}$ is 1.8 [61,64], suggesting a weaker interaction with the amine side-chains of pAH.

We extended our investigation to include a wider range of sodium salts to further evaluate the effects of various monovalent anions. An examination of turbidity as a function of sodium halide concentration (Figure 4a) suggests a decrease in critical salt concentration with increasing atomic weight of the halide anion (i.e., $\mathrm{Cl}^{-}>\mathrm{Br}^{-}>\mathrm{I}$ ). This follows the Hofmeister series, which trends from $\mathrm{Cl}^{-}$as a moderately inert anion to $\mathrm{I}^{-}$as a chaotrope (i.e., tending to increase polymer solubility) [55,65]. This observation of decreasing critical salt concentration matches well with the concomitant increases in polymer solubility from the various ions. Higher polymer solubility will tend to destabilize the [55] phase 
separation and, thus, disfavor coacervate formation. These trends also match ordering of interactions predicted by HSAB [59] and ion-water affinity measurements [61,64].

Figure 4. Plots of turbidity showing a comparison of varying monovalent sodium salts as a function of salt concentration for (a) a halide series and (b) other monovalent anions. All samples were prepared at $1 \mathrm{mM}$ total monomer concentration, 50/50 mol\% $\mathrm{pAA} / \mathrm{pAH}$ ratio at $\mathrm{pH}$ 6.5. Complexes were prepared by adding pAA to a solution containing a mixture of pAH and the desired quantity of salt.
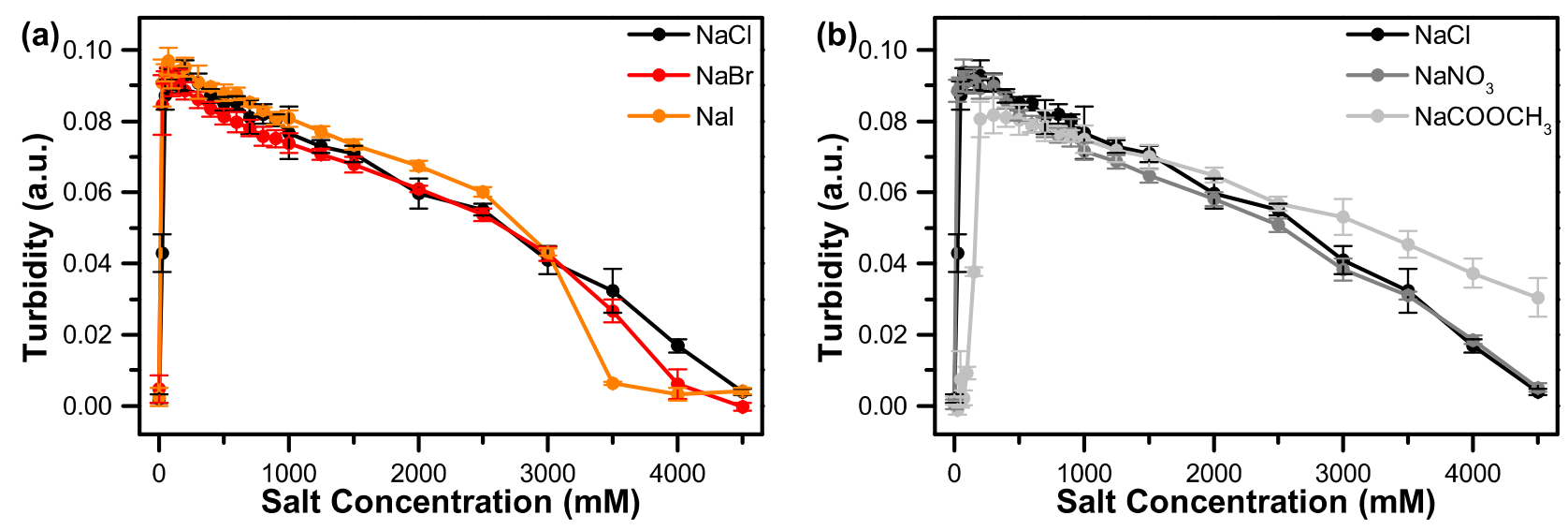

Figure $4 \mathrm{~b}$ shows a similar comparison of $\mathrm{NaCl}$ with the sodium salts of two molecular anions, $\mathrm{NO}_{3}{ }^{-}$ and $\mathrm{CH}_{3} \mathrm{COO}^{-}$. Here, we observed very little difference in the turbidity plots for $\mathrm{NaCl}$ and $\mathrm{NaNO}_{3}$, in relative agreement with the ordering of the Hofmeister series of anions and HSAB designations [55,59]. Both $\mathrm{Cl}^{-}$and $\mathrm{NO}_{3}{ }^{-}$have ADHN of zero, but direct comparison of additional affinity parameters such as the Jones-Dole viscosity B-coefficient are complicated due to the differences in size between a $\mathrm{Cl}^{-}$ ion and molecular $\mathrm{NO}_{3}^{-}$[61,64]. Interestingly, the data for $\mathrm{NaCOOCH}_{3}$ (Figure 4b) suggest a significantly higher critical salt concentration, similar to the trends observed for $\mathrm{Na}_{2} \mathrm{SO}_{4}$ as a function of ionic strength (Figure $3 \mathrm{~b}$ ). Here, the kosmotropic tendency of $\mathrm{SO}_{4}{ }^{2-}$ and $\mathrm{CH}_{3} \mathrm{COO}^{-}$decreases polymer solubility, thus enhancing phase separation [65]. The fact that very similar behavior is observed for $\mathrm{SO}_{4}{ }^{2-}$ and $\mathrm{CH}_{3} \mathrm{COO}^{-}$at equivalent ionic strengths (Figure 5) further confirms the idea that, while salt valence dominates interactions with coacervates, more subtle effects can be correctly predicted based on correlations, such as the Hofmeister series.

While Hofmeister effects are typically more pronounced for anions [55], we also investigated series of different chloride salts (i.e., $\mathrm{NaCl}, \mathrm{KCl}, \mathrm{MgCl}_{2}, \mathrm{CaCl}_{2}$ ) to examine cation effects (Figure 6). As was indicated previously, the overall charge of the ion dominates its interaction with the coacervate. However, examination of the turbidity data clearly demonstrates a difference in the interaction of the various cations with the $\mathrm{pAA} / \mathrm{pAH}$ system. The observed trends in critical salt concentration (or critical ionic strength) correlate directly with the expected Hofmeister ordering (i.e., $\mathrm{K}^{+}>\mathrm{Na}^{+}>\mathrm{Mg}^{2+}>\mathrm{Ca}^{2+}$ ), where $\mathrm{K}^{+}$shows the highest salt stability and $\mathrm{Ca}^{2+}$ shows the lowest [65]. It is interesting that the magnitude of the effect of the various cations on the critical salt concentration was comparable to that observed for anions, whereas typically anionic Hofmeister effects are expected to dominate a system. 
Figure 5. Plot of turbidity as a function of ionic strength, showing a comparison between $\mathrm{NaCOOCH}_{3}$ and $\mathrm{Na}_{2} \mathrm{SO}_{4}$. All samples were prepared at $1 \mathrm{mM}$ total monomer concentration, $50 / 50 \mathrm{~mol} \% \mathrm{pAA} / \mathrm{pAH}$ ratio at $\mathrm{pH}$ 6.5. Complexes were prepared by adding pAA to a solution containing a mixture of $\mathrm{pAH}$ and the desired quantity of salt.

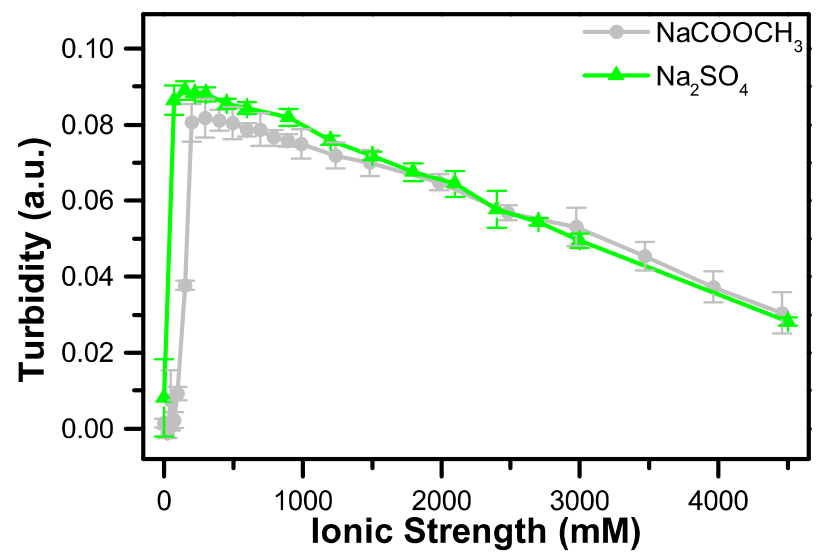

Figure 6. Plots of turbidity as a function of (a) salt concentration and (b) ionic strength for a series of chloride salts, investigating the effects of various cations. All samples were prepared at $1 \mathrm{mM}$ total monomer concentration, 50/50 mol\% $\mathrm{pAA} / \mathrm{pAH}$ ratio at $\mathrm{pH} 6.5$. Complexes were prepared by adding pAA to a solution containing a mixture of $\mathrm{pAH}$ and the desired quantity of salt.


We further expanded our comparison of cation effects to include a variety of different sodium and potassium salts (Figure 7). These two cations are of particular biological interest because they are (i) the two most abundant monovalent cations in living organisms and (ii) the specificity of $\mathrm{Na}^{+}$versus $\mathrm{K}^{+}$ is known to play a critical role in many biological processes [31]. While the solubility of potassium salts limited the concentration range that could be examined, the same trends observed for $\mathrm{NaCl} / \mathrm{KCl}$ (Figure 7b) were present for $\mathrm{NaNO}_{3} / \mathrm{KNO}_{3}$ (Figure 7c) and $\mathrm{Na}_{2} \mathrm{SO}_{4} / \mathrm{K}_{2} \mathrm{SO}_{4}$ (Figure $7 \mathrm{~d}$ ). Regardless of anion, the turbidity data consistently suggests enhancement of coacervate stability in the presence of potassium salts, compared to sodium salts. Furthermore, the overall trends discussed previously with regards to the effects of the various anions held true for both sodium and potassium salts, suggesting that the effects of the various ions can be treated in an additive fashion. 
Figure 7. (a) A plot of turbidity as a function of salt concentration, showing a comparison of different pairs of sodium and potassium salts, which are highlighted individually in (b-d) as a function of ionic strength for (b) $\mathrm{NaCl} / \mathrm{KCl}$, (c) $\mathrm{NaNO}_{3} / \mathrm{KNO}_{3}$, and (d) $\mathrm{Na}_{2} \mathrm{SO}_{4} / \mathrm{K}_{2} \mathrm{SO}_{4}$. All samples were prepared at $1 \mathrm{mM}$ total monomer concentration, $50 / 50 \mathrm{~mol} \% \mathrm{pAA} / \mathrm{pAH}$ ratio at $\mathrm{pH}$ 6.5. Complexes were prepared by adding $\mathrm{pAA}$ to a solution containing a mixture of $\mathrm{pAH}$ and the desired quantity of salt.
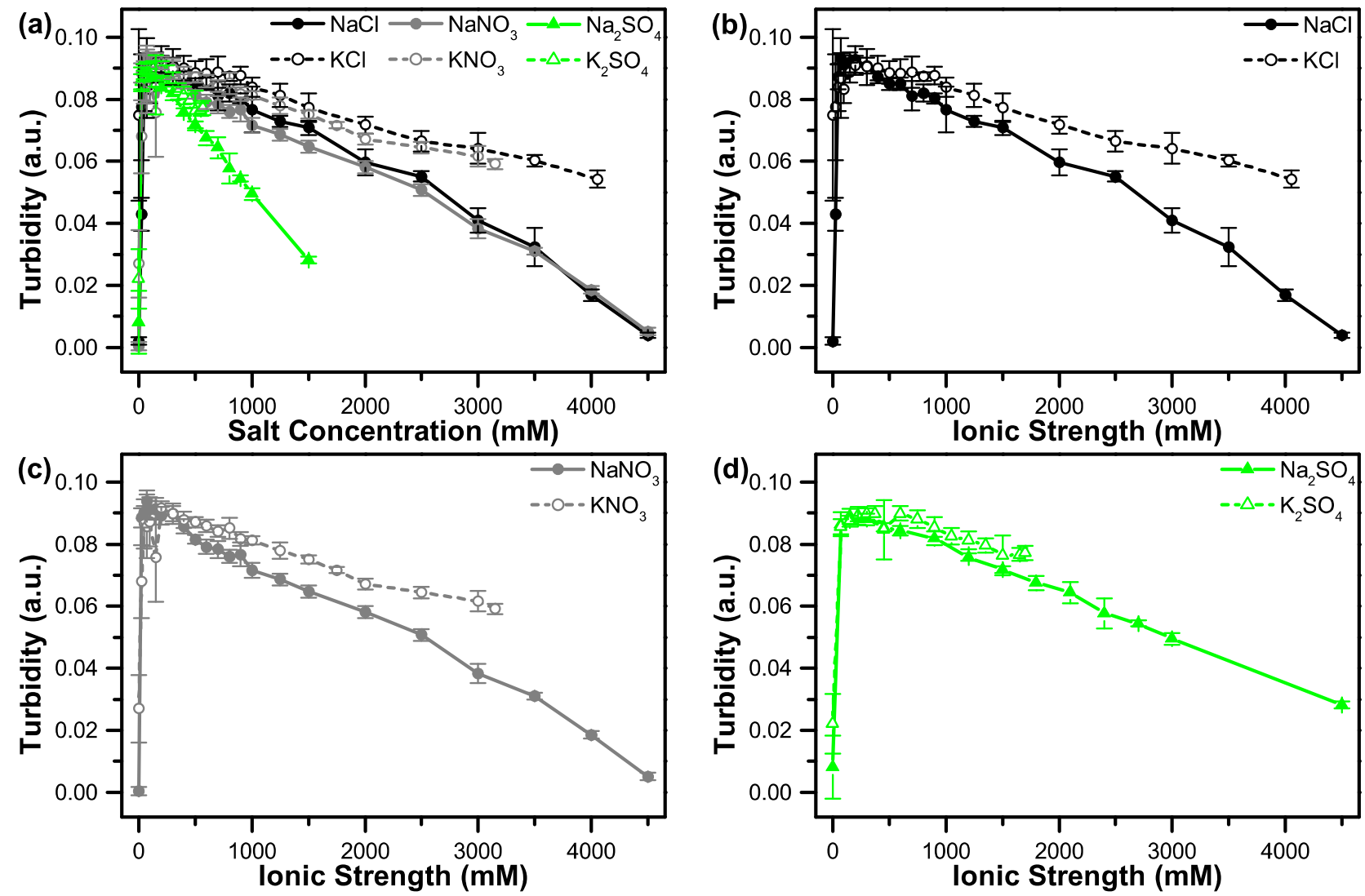

\subsection{The Effect of pH on Coacervate Salt Stability}

Finally, we returned to the idea of polymer charge density by investigating the effect of salt on coacervate formation at different $\mathrm{pH}$ conditions. The data presented in Section 3.2 was collected at $\mathrm{pH}$ 6.5, where both pAA and pAH are assumed to be fully charged. However, $\mathrm{pH} 8.5$ corresponds to the $\mathrm{pKa}$ for $\mathrm{pAH}$, meaning that $\mathrm{pAH}$ is only half-charged, while pAA remains fully charged. In Section 3.1 we demonstrated that an increase in complex formation and broadening of the coacervation window occurred in the presence of low concentrations of salt at both $\mathrm{pH}$ conditions. However, the data presented in Section 3.2 suggested that turbidity is only sensitive to variations in complexation in the high and low salt limits.

Figure 8 shows a plot of turbidity as a function of $\mathrm{NaCl}$ concentration for coacervates prepared at pH 6.5 (filled) and pH 8.5 (open). With increasing pH there is a distinct decrease in the observed critical salt concentration. This matches well with predictions based on the Voorn-Overbeek theory, which suggest that the critical salt concentration decreases with decreasing charge density $[11,12,44]$. However, the same trends regarding salt valence and type were observed at $\mathrm{pH} 8.5$ (Figure 9) 
compared to $\mathrm{pH} 6.5$ (Figure 3), albeit in convolution with the decreases in critical salt concentration resulting from polymer charge density effects.

Figure 8. Plot of turbidity as a function of $\mathrm{NaCl}$ concentration at $\mathrm{pH} 6.5$ where both polymers are fully charged (closed) and $\mathrm{pH} 8.5$ where the pAA is half-charged (open). All samples were prepared at $1 \mathrm{mM}$ total monomer concentration, and charge-neutral conditions (50/50 mol\% $\mathrm{pAA} / \mathrm{pAH}$ at $\mathrm{pH} 6.5$ and 33/67 mol\% $\mathrm{pAA} / \mathrm{pAH}$ at $\mathrm{pH} 8.5)$. Complexes were prepared by adding pAA to a solution containing a mixture of $\mathrm{pAH}$ and the desired quantity of salt.

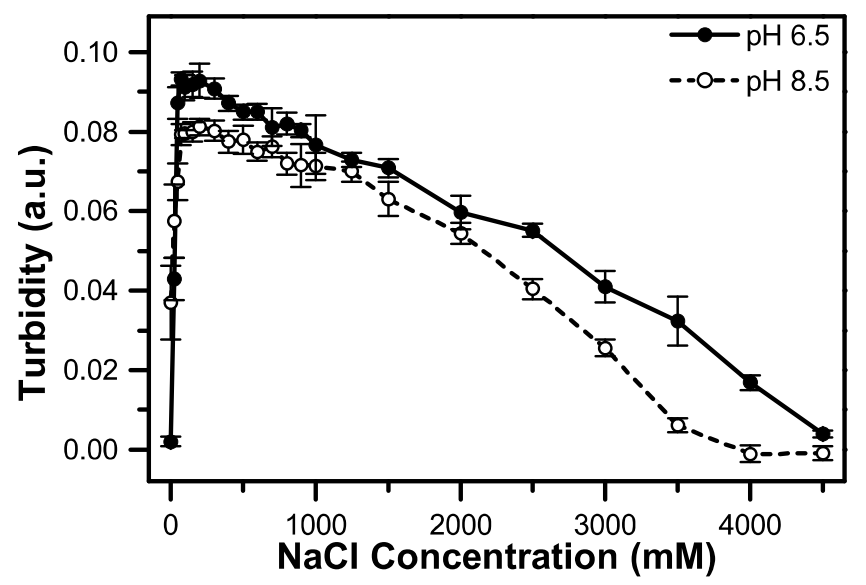

Figure 9. Plots of turbidity as a function of (a) salt concentration and (b) ionic strength for a selection of monovalent and divalent salts. All samples were prepared at $1 \mathrm{mM}$ total monomer concentration, 33/67 mol\% $\mathrm{pAA} / \mathrm{pAH}$ ratio at $\mathrm{pH} 8.5$. Complexes were prepared by adding pAA to a solution containing a mixture of pAH and the desired quantity of salt.
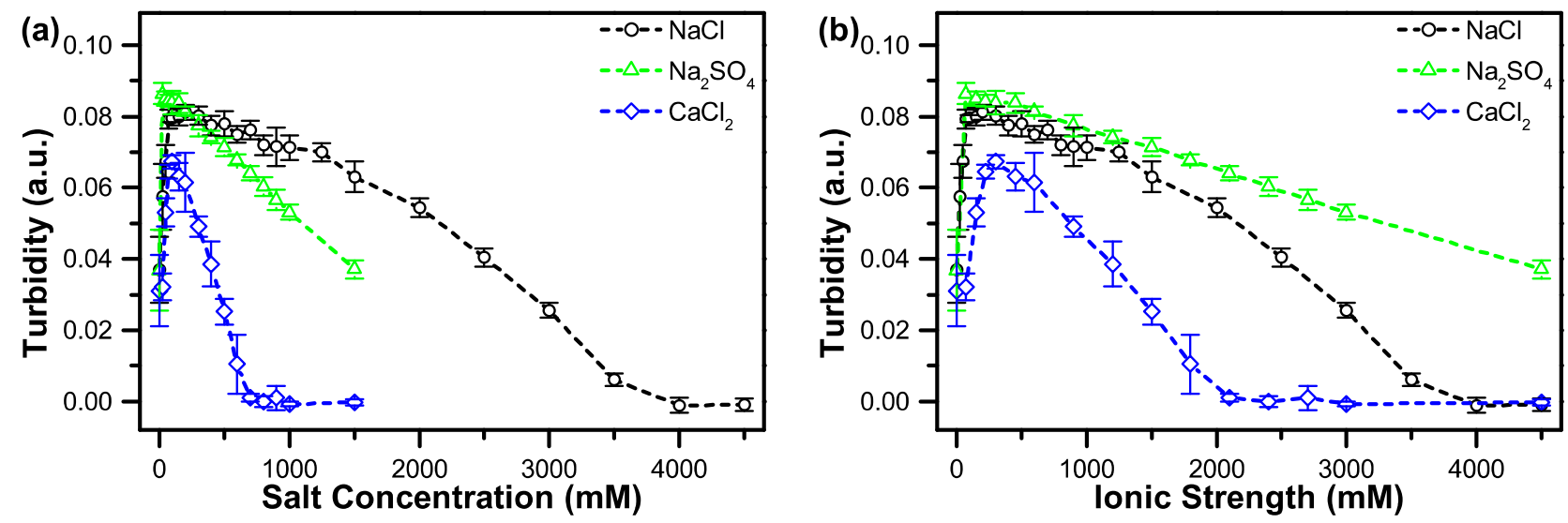

\section{Conclusions}

Overall, we confirmed the dominant role that overall polyelectrolyte charge plays in determining the extent of complex coacervation via turbidimetric analysis of a matched pair of vinyl polyelectrolytes $(\mathrm{pAA} / \mathrm{pAH})$ at well-defined $\mathrm{pH}$ conditions to minimize the number of potential variables and allow for unambiguous interpretation of the data. Maximum complex formation was observed at polymer compositions corresponding to charge neutrality. In the symmetric case of two 
equally charged polymers this maximum occurred at 50/50 mol\% pAA/pAH. However, for the asymmetric case where pAA remained fully charged, but pAH was only half-charged, the maximum shifted to $33 / 67 \mathrm{~mol} \% \mathrm{pAA} / \mathrm{pAH}$ because of the increased number of $\mathrm{pAH}$ chains needed for charge neutrality.

The effect of salt on coacervation also depended strongly on the overall charge of the ions, although significant secondary, Hofmeister-like effects were also observed. For instance, a significant decrease in the critical salt concentration was observed for divalent as compared to monovalent salts. However, this decrease in the critical salt concentration could not be attributed solely to the effects of ionic strength. Divalent cations were found disfavor coacervate formation more strongly than divalent anions. These differences were explained based on the size and charge density of the ions, as well as their hardness and solvation. These observations based on HSAB theory also agreed well with trends expected from the Hofmeister series. In particular, chaotropic ions, such as $\mathrm{I}^{-}$and $\mathrm{Ca}^{2+}$, which are characterized by a tendency to "salt in," or increase the solubility of polymers, tended to decrease the critical salt concentration. Conversely, kosmotropes were observed to increase the critical salt concentration by lowering the polymer solubility and thus favoring phase separation. Decreases in polymer charge density as a result of $\mathrm{pH}$ changes were also shown to affect the absolute value of the critical salt concentration, although not the overall trends observed for various salts.

These results have the potential to enable the informed design of coacervate-based systems for use in complex ionic environments. We have demonstrated that electrostatic effects related to the polymers and various combinations of cations and anions are, in fact, additive, and can be predicted based on a combination of overall charge and Hofmeister-like behavior. More detailed investigations of the effect of salt on the thermodynamics of complexation and the internal polymeric structure of the coacervate phases are underway, as are theoretical investigations designed to capture both overall charge effects and ion-specific subtleties. It would also be particularly informative to characterize transient effects, such as the addition of salt to a pre-equilibrated coacervate system. The development of a framework for the straightforward design of coacervate-based materials in complicated ionic environments has significant potential to improve their application in a wide range of fields.

\section{Acknowledgments}

This work benefited from discussions with Charles E. Sing, Jian Qin, Jonathan K. Whitmer, Matthew J. Kade, and Juan J. de Pablo. This work was supported by the University of Chicago and the U.S. Department of Energy Office of Science program in Basic Energy Sciences and the Materials Sciences and Engineering Division.

\section{Author Contributions}

Sarah Perry designed all experiments, performed data analysis, and prepared the manuscript. Yue Li prepared all solutions and performed the experiments. Dimitris Priftis, Lorraine Leon, and Matthew Tirrell contributed to the interpretation of results and preparation of the manuscript.

\section{Conflicts of Interest}

The authors declare no conflict of interest. 


\section{References}

1. Spruijt, E.; Westphal, A.H.; Borst, J.W.; Cohen Stuart, M.A.; van der Gucht, J. Binodal compositions of polyelectrolyte complexes. Macromolecules 2010, 43, 6476-6484.

2. Van der Gucht, J.; Spruijt, E.; Lemmers, M.; Cohen Stuart, M.A. Polyelectrolyte complexes: Bulk phases and colloidal systems. J. Colloid Interface Sci. 2011, 361, 407-422.

3. Biesheuvel, P.M.; Cohen Stuart, M.A. Electrostatic free energy of weakly charged macromolecules in solution and intermacromolecular complexes consisting of oppositely charged polymers. Langmuir 2004, 20, 2785-2791.

4. Priftis, D.; Tirrell, M. Phase behaviour and complex coacervation of aqueous polypeptide solutions. Soft Matter 2012, 8, 9396-9405.

5. Priftis, D.; Megley, K.; Laugel, N.; Tirrell, M. Complex coacervation of poly (ethyleneimine)/polypeptide aqueous solutions: Thermodynamic and rheological characterization. J. Colloid Interface Sci. 2013, 398, 39-50.

6. Priftis, D.; Laugel, N.; Tirrell, M. Thermodynamic characterization of polypeptide complex coacervation. Langmuir 2012, 28, 15947-15957.

7. Pergushov, D.V.; Müller, A.H.E.; Schacher, F.H. Micellar interpolyelectrolyte complexes. Chem. Soc. Rev. 2012, 41, 6888-6901.

8. Priftis, D.; Farina, R.; Tirrell, M. Interfacial energy of polypeptide complex coacervates measured via capillary adhesion. Langmuir 2012, 28, 8721-8729.

9. Chollakup, R.; Smitthipong, W.; Eisenbach, C.D.; Tirrell, M. Phase behavior and coacervation of aqueous poly(acrylic acid)-poly(allylamine) solutions. Macromolecules 2010, 43, 2518-2528.

10. Chollakup, R.; Beck, J.B.; Dirnberger, K.; Tirrell, M.; Eisenbach, C.D. Polyelectrolyte molecular weight and salt effects on the phase behavior and coacervation of aqueous solutions of poly(acrylic acid) sodium salt and poly(allylamine) hydrochloride. Macromolecules 2013, 46, 2376-2390.

11. Priftis, D.; Xia, X.; Margossian, K.O.; Perry, S.L.; Leon, L.; Qin, J.; de Pablo, J.J.; Tirrell, M. Ternary, tunable polyelectrolyte complex fluids driven by complex coacervation. Macromolecules 2014, 47, 3076-3085.

12. Qin, J.; Priftis, D.; Farina, R.; Perry, S.L.; Leon, L.; Whitmer, J.K.; Hoffman, K.Q.; Tirrell, M.; de Pablo, J.J. Interfacial tension of polyelectrolyte complex coacervate phases. ACS Macro Lett. 2014, 3, 565-568.

13. Kayitmazer, A.B.; Strand, S.P.; Tribet, C.; Jaeger, W.; Dubin, P.L. Effect of polyelectrolyte structure on protein-polyelectrolyte coacervates: Coacervates of bovine serum albumin with poly(diallyldimethylammonium chloride) versus chitosan. Biomacromolecules 2007, 8, 3568-3577.

14. Kayitmazer, A.B.; Seeman, D.; Minsky, B.B.; Dubin, P.L.; Xu, Y. Protein-polyelectrolyte interactions. Soft Matter 2013, 9, 2553-2583.

15. Jewell, C.M.; Lynn, D.M. Multilayered polyelectrolyte assemblies as platforms for the delivery of DNA and other nucleic acid-based therapeutics. Adv. Drug Deliv. Rev. 2008, 60, 979-999.

16. Jewell, C.M.; Lynn, D.M. Surface-mediated delivery of DNA: Cationic polymers take charge. Curr. Opin. Colloid Interface Sci. 2008, 13, 395-402. 
17. Chu, H.; Gao, J.; Chen, C.-W.; Huard, J.; Wang, Y. Injectable fibroblast growth factor-2 coacervate for persistent angiogenesis. Proc. Natl. Acad. Sci. USA 2011, 108, 13444-13449.

18. Pittella, F.; Kataoka, K. Polymeric micelles for siRNA delivery. In Advances in Delivery Science and Technology; Howard, K.A., Ed.; Springer: Berlin, Germany, 2012; pp. 161-184.

19. Hwang, D.S.; Waite, J.H.; Tirrell, M. Promotion of osteoblast proliferation on complex coacervation-based hyaluronic acid-Recombinant mussel adhesive protein coatings on titanium. Biomaterials 2010, 31, 1080-1084.

20. Hammond, P.T. Form and function in multilayer assembly: New applications at the nanoscale. Adv. Mater. 2004, 16, 1271-1293.

21. Laugel, N.; Betscha, C.; Winterhalter, M.; Voegel, J.C.; Schaaf, P.; Ball, V. Relationship between the growth regime of polyelectrolyte multilayers and the polyanion/polycation complexation enthalpy. J. Phys. Chem. B 2006, 110, 19443-19449.

22. Schmitt, C.; Turgeon, S.L. Protein/polysaccharide complexes and coacervates in food systems. Adv. Colloid Interface Sci. 2011, 167, 63-70.

23. Stewart, R.J.; Wang, C.S.; Shao, H. Complex coacervates as a foundation for synthetic underwater adhesives. Adv. Colloid Interface Sci. 2011, 167, 85-93.

24. Lim, S.; Moon, D.; Kim, H.J.; Seo, J.H.; Kang, I.S.; Cha, H.J. Interfacial tension of complex coacervated mussel adhesive protein according to the Hofmeister series. Langmuir 2014, 30, $1108-1115$.

25. Lim, S.; Choi, Y.S.; Kang, D.G.; Song, Y.H.; Cha, H.J. The adhesive properties of coacervated recombinant hybrid mussel adhesive proteins. Biomaterials 2010, 31, 3715-3722.

26. Hwang, D.S.; Zeng, H.; Srivastava, A.; Krogstad, D.V.; Tirrell, M.; Israelachvili, J.N.; Waite, J.H. Viscosity and interfacial properties in a mussel-inspired adhesive coacervate. Soft Matter 2010, 6, 3232-3236.

27. Hwang, D.S.; Zeng, H.; Lu, Q.; Israelachvili, J.; Waite, J.H. Adhesion mechanism in a DOPA-deficient foot protein from green mussels. Soft Matter 2012, 8, 5640-5648.

28. Fulton, A.B. How crowded is the cytoplasm? Cell 1982, 30, 345-347.

29. Zimmerman, S.B.; Trach, S.O. Estimation of macromolecule concentrations and excluded volume effects for the cytoplasm of Escherichia coli. J. Mol. Biol. 1991, 222, 599-620.

30. Minton, A.P. Excluded volume as a determinant of macromolecular structure and reactivity. Biopolymers 1981, 20, 2093-2120.

31. Vrbka, L.; Vondrášek, J.; Jagoda-Cwiklik, B.; Vácha, R.; Jungwirth, P. Quantification and rationalization of the higher affinity of sodium over potassium to protein surfaces. Proc. Natl. Acad. Sci. USA 2006, 103, 15440-15444.

32. Nic, M.; Jirat, J.; Kosata, B. IUPAC Compendium of Chemical Terminology, 2nd ed.; McNaught, A.D., Wilkinson, A., Eds.; Blackwell Scientific Publications: Oxford, UK, 1997.

33. Spruijt, E.; Sprakel, J.; Cohen Stuart, M.A.; van der Gucht, J. Interfacial tension between a complex coacervate phase and its coexisting aqueous phase. Soft Matter 2010, 6, 172-178.

34. Spruijt, E.; Cohen Stuart, M.A.; van der Gucht, J. Linear viscoelasticity of polyelectrolyte complex coacervates. Macromolecules 2013, 46, 1633-1641.

35. De Kruif, C.G.; Weinbreck, F.; de Vries, R. Complex coacervation of proteins and anionic polysaccharides. Curr. Opin. Colloid. Interface Sci. 2004, 9, 340-349. 
36. Burgess, D.J. Practical analysis of complex coacervate systems. J. Colloid Interface Sci. 1990, 140, 227-238.

37. Castelnovo, M.; Joanny, J.F. Complexation between oppositely charged polyelectrolytes: Beyond the random phase approximation. Eur. Phys. J. E Soft Matter Biol. Phys. 2001, 6, 377-386.

38. Ou, Z.; Muthukumar, M. Entropy and enthalpy of polyelectrolyte complexation: Langevin dynamics simulations. J. Chem. Phys. 2006, 124, doi:10.1063/1.2178803.

39. Dautzenberg, H.; Kriz, J. Response of polyelectrolyte complexes to subsequent addition of salts with different cations. Langmuir 2003, 19, 5204-5211.

40. Tainaka, K.-I. Effect of counterions on complex coacervation. Biopolymers 1980, 19, 1289-1298.

41. Bucur, C.B.; Sui, Z.; Schlenoff, J.B. Ideal mixing in polyelectrolyte complexes and multilayers: Entropy driven assembly. J. Am. Chem. Soc. 2006, 128, 13690-13691.

42. Anema, S.G.; de Kruif, C.G.K. Co-acervates of lactoferrin and caseins. Soft Matter 2012, 8, 4471-4478.

43. Anema, S.G.; de Kruif, C.G.K. Coacervates of lysozyme and $\beta$-casein. J. Colloid Interface Sci. 2013, 398, 255-261.

44. Overbeek, J.T.G.; Voorn, M.J. Phase separation in polyelectrolyte solutions. Theory of complex coacervation. J. Cell. Comp. Physiol. 1957, 49, 7-26.

45. Weinbreck, F.; de Vries, R.; Schrooyen, P.; de Kruif, C.G. Complex coacervation of whey proteins and gum arabic. Biomacromolecules 2003, 4, 293-303.

46. Krogstad, D.V.; Lynd, N.A.; Choi, S.-H.; Spruell, J.M.; Hawker, C.J.; Kramer, E.J.; Tirrell, M.V. Effects of polymer and salt concentration on the structure and properties of triblock copolymer coacervate hydrogels. Macromolecules 2013, 46, 1512-1518.

47. Spruijt, E.; Leermakers, F.A.M.; Fokkink, R.; Schweins, R.; van Well, A.A.; Cohen Stuart, M.A.; van der Gucht, J. structure and dynamics of polyelectrolyte complex coacervates studied by scattering of neutrons, X-rays, and light. Macromolecules 2013, 46, 4596-4605.

48. Dautzenberg, H.; Karibyants, N. Polyelectrolyte complex formation in highly aggregating systems. Effect of salt: Response to subsequent addition of NaCl. Macromol. Chem. Phys. 1999, 200, 118-125.

49. Lindhoud, S.; de Vries, R.; Schweins, R.; Cohen Stuart, M.A.; Norde, W. Salt-induced release of lipase from polyelectrolyte complex micelles. Soft Matter 2009, 5, 242-250.

50. Lindhoud, S.; Voorhaar, L.; de Vries, R.; Schweins, R.; Stuart, M.A.C.; Norde, W. Salt-induced disintegration of lysozyme-containing polyelectrolyte complex micelles. Langmuir 2009, 25, $11425-11430$.

51. Voets, I.K.; de Keizer, A.; Stuart, M.A.C. Complex coacervate core micelles. Adv. Colloid Interface Sci. 2009, 147-148, 300-318.

52. Overbeek, J.T.G.; Bungenberg de Jong, H.G. Sols of Macromolecular Colloids with Electrolytic Nature. In Colloid Science; Kruyt, H., Ed.; Elsevier Publishing Company: New York, NY, USA, 1949; pp. 184-231.

53. Weinbreck, F.; Nieuwenhuijse, H.; Robijn, G.W.; de Kruif, C.G. Complexation of whey proteins with carrageenan. J. Agric. Food Chem. 2004, 52, 3550-3555.

54. Kunz, W.; Lo Nostro, P.; Ninham, B.W. The present state of affairs with Hofmeister effects. Curr. Opin. Colloid. Interface Sci. 2004, 9, 1-18. 
55. Zhang, Y.; Cremer, P.S. Interactions between macromolecules and ions: The Hofmeister series. Curr. Opin. Chem. Biol. 2006, 10, 658-663.

56. Tagliazucchi, M.; Olvera de la Cruz, M.; Szleifer, I. Self-organization of grafted polyelectrolyte layers via the coupling of chemical equilibrium and physical interactions. Proc. Natl. Acad. Sci. U.S.A. 2010, 107, 5300-5305.

57. Carlsson, F.; Linse, P.; Malmsten, M. Monte Carlo simulations of polyelectrolyte-protein complexation. J. Phys. Chem. B 2001, 105, 9040-9049.

58. Pearson, R.G. Hard and soft acids and bases. J. Am. Chem. Soc. 1963, 85, 3533-3539.

59. Pearson, R.G. Hard and soft acids and bases, HSAB, part I: Fundamental principles. J. Chem. Educ. 1968, 45, 581-587.

60. Hofmeister, F. Zur Lehre von der Wirkung der Salze. Archiv f. experiment. Pathol. u. Pharmakol. 1888, 25, 1-30. (In German)

61. Collins, K.D. Ion hydration: Implications for cellular function, polyelectrolytes, and protein crystallization. Biophys. Chem. 2006, 119, 271-281.

62. Collins, K.D. Charge density-dependent strength of hydration and biological structure. Biophys. J. 1997, 72, 65-76.

63. Collins, K.D. Ions from the Hofmeister series and osmolytes: Effects on proteins in solution and in the crystallization process. Methods 2004, 34, 300-311.

64. Kiriukhin, M.Y.; Collins, K.D. Dynamic hydration numbers for biologically important ions. Biophys. Chem. 2002, 99, 155-168.

65. Cacace, M.G.; Landau, E.M.; Ramsden, J.J. The Hofmeister series: Salt and solvent effects on interfacial phenomena. Q. Rev. Biophys. 1997, 30, 241-277.

(C) 2014 by the authors; licensee MDPI, Basel, Switzerland. This article is an open access article distributed under the terms and conditions of the Creative Commons Attribution license (http://creativecommons.org/licenses/by/3.0/). 